\title{
Price volatility and market performance measures: The case of revenue managed goods
}

\author{
Benny Mantin a and Eran Rubin ${ }^{\mathrm{b}}$ \\ a Luxembourg Centre for Logistics and Supply Chain Management, University of Luxembourg, \\ Luxembourg, benny.mantin@uni.lu \\ b Department of Management, College of Business Administration, The University of Akron, \\ Akron, Ohio, U.S.A, erubin@uakron.edu
}

\begin{abstract}
Revenue management systems (RM) dynamically update product prices in order to optimize for revenue. When such systems are used by the companies participating in a market, the RM operational outcome is manifested in volatile market prices. In this paper, we assess the use of a market's price-volatility level as a possible tool to evaluate market performance. In the airline industry, the degree of price volatility varies dramatically across different markets. We quantify the relationship between these volatility levels and various route-level performance metrics: transacted fares, sales (fill rate) and revenue. Using data on US domestic aviation markets, we find that markets with higher levels of price volatility are associated with higher levels of transacted fares, lower aircrafts’ fill rates, higher revenues, and higher degrees of transacted fare dispersion.
\end{abstract}

Keywords: revenue management, market performance assessment, dynamic pricing, price volatility, airline industry 


\section{Introduction}

Revenue Management (RM) systems support sellers in maximizing their revenue under the inherit tradeoff conditions they face. Namely, sellers strive to sell their products to those customers who value them highly, so that high margins can be achieved. However, if the sellers wait too long for those high valuation customers to appear, they might end up with unsold units that could have been sold to customers with lower valuations. This trade-off emerges in numerous industries. For example, in the travel industry, business passengers tend to finalize their travel plans closer to the travel date, and leisure passengers make their travel arrangements well in advance. Revenue optimization under such variations in demand characteristics is under the scope of RM systems.

In the airline industry, fare classes are the mechanism underlying RM practices. Fare classes are designed to target different consumer segments based on consumers' characteristics, such as valuations, time and price sensitivity. The prices of these fare classes are often determined well in advance, and in realtime RM systems dynamically control the availability of the different fare classes, based, among others, on the realization of demand, time to departure, and updated demand forecasts. With the rapid development of information technologies and the growth of e-commerce, RM systems incorporate a greater level of sophistication and velocity, which, coupled with the lower costs associated with these fare-related adjustments (Brynjolfsson and Smith, 2000), can translate into frequent updates to the availability of fare classes.

The mere use of RM does not mandate a uniform degree of price volatility levels across markets. As we show in this research, the reality is quite the opposite: different markets exhibit significantly different price volatility levels. These differences in price volatility essentially suggest that the RM and pricing decisions commanded by RM systems vary, quite dramatically, across markets. The research question guiding this work is to what extent do these differences in price volatility embody new information from which decision makers can infer about market performance variables, and to what extent can these differences be explained by conventional market characteristics? Understanding the relationship between price volatility and market performance measures can potentially help assess market efficiencies and 
competitive environments. This can guide both carriers, when assessing their operations in different markets, and consumers as they try to behave strategically in timing their ticket purchase.

We examine the relationship between market price volatility and several commonly used performance measures in the airline industry: average transacted fare normalized for the distance (referred to as yield, or Revenue per Passenger Kilometer, or RPK); the dispersion of the transacted fares as measured by the Gini coefficient; fill rate, which captures the proportion of seats sold on flights (also referred to as load factor); as well as a measurement of the average revenue generated from each seat on the plane per unit of distance, which is the product of yield and load factor. This measure is also known as Revenue per Available Seat Kilometer, or RASK.

We also seek evidence for the role of volatility in affecting consumer behavior. The marketing literature has shown in the context of staple goods that price volatility may impact consumers' price valuation (and reference price) of the product. When purchasing staple goods, consumers generally become less sensitive to prices (Volkmann, 1951; Janiszewski and Lichtenstein, 1999) and less certain about the reference price (Winer, 1989). Consequently, they may be willing to accept a larger range of prices (Dickson and Sawyer, 1990; Winer 1986; Rao and Sieben, 1992; Kalyanaram and Little,1994). If similar consumer behavior effects exist in the context of RM goods, carriers may be able to generate more revenue as an outcome of volatility.

Using a database consisting of posted fares in several hundred US domestic routes we quantify the magnitude of price volatility in the various markets. First, we find that a higher level of price volatility is associated with a larger Gini coefficient of transacted fares. While this relationship between volatility of posted prices and dispersion of transaction prices may not be surprising, this result is interesting as the relationship between variations of posted prices and dispersion of transacted prices was not established previously in the context of airfares. We also find that, after controlling for market and competition characteristics, higher levels of price volatility in a market are associated with higher transacted fares for each kilometer flown. With respect to fill rates, we find that they are significantly lower in markets with more volatile fares. As we witness higher average transacted fares but lower fill rates, the ultimate question 
arises: Are volatile markets associated with higher revenue rates? Our empirical estimation reveals that airlines' revenues rates are higher in the markets exhibiting more price volatility. That is, the higher transacted fares associated with higher fare volatility compensate for the reduced fill rates. By applying a two-stage model, estimating market fare volatility and posted prices in the first stage and revenue in the

second, we find evidence that price sensitive consumers behave differently in volatile markets, enabling carriers to generate increased revenues. While price volatility does not induce revenue in business markets, in leisure markets it may help derive higher revenues.

The remainder of this paper is organized as follows. In Section 2 we review the literature on sources of price volatility. In Section 3 we consider the implications of price volatility with an emphasis on the airline industry. Section 4 introduces the data used for the empirical analysis. The main empirical estimations are carried out in Section 5, whereas Section 6 addresses issues relating to consumer behavior. Section 7 concludes.

\section{Revenue Management and sources of price volatility}

The classic RM setting (Netessine and Shumsky, 2002) considers a seller who (i) is endowed with a limited inventory of a perishable good; (ii) commits to sales while facing uncertainty about future demand; (iii) faces different distinguishable demand segments, enabling separate fare rules and restrictions; (iv) can sell the same unit of inventory to any demand segment; and (v) seeks to maximize profit. The emerging revenue maximizing solution is such that the seller designs fare classes that correspond to the different demand segments, and these fare classes are opened and closed over time in response to the changing demand (Belobaba, 1989). A rich literature on revenue management has emerged from this revenue maximization problem, see, e.g., reviews by Talluri and van Ryzin (2004) Phillips (2005) and Bodea and Ferguson (2014).

An important outcome of revenue management methods, is the fluctuation of prices as fare classes are reopened or reclosed (MaAfee and te Velde, 2007; Anderson and Wilson 2003). This is important since the level of fluctuation informs us on the dynamics in the market. It is possible that merely from observing fluctuation levels, one may be able to assess market performance. Fluctuating prices may also affect consumers purchasing behavior. While volatile prices are common in revenue managed goods, consumers’ 
response to fluctuating prices of revenue managed goods has mostly been ignored. Revenue management practices may have similar effects to those modeled under the context of mixed price strategies, which we describe next.

Mixed pricing is commonly used by firms to discriminate between a heterogeneous pool of consumers, typically informed and uninformed, to establish market segmentation. Various models have shown that mixed pricing strategies would be adopted in equilibrium and thus give rise to volatile prices, both in monopolistic and competitive environments. For example, in Varian's (1980) seminal model it is optimal for the stores to randomize their prices in order to price discriminate between informed and uniformed consumers. In a related model, Baye and Morgan (2001) develop a theory of information gate-keepers (e.g., an Internet platform), who charge sellers as well as buyers access fees. In equilibrium, the firms that join the gate-keepers (and advertise) adopt a mixed pricing strategy. Chioveanu and Zhou (2013) show the persistence of mixed pricing strategies when retailers also compete in their price frames (such as presenting the price in terms of weight vs volume). In their model, the randomization of price frames is utilized to obfuscate price comparisons.

Extending the concept of market segmentation and mixed pricing with the notion of loyal consumers, garnered an ongoing attention to the relationship between firms' intertemporal pricing strategies, and their price promotion strategies (e.g., Raju et al., 1990). Narasimhan (1988) studies the depth and frequency of discounts in a model with loyal consumers and brand switchers. Sinitsyn (2008) shows that mixed pricing over a fixed number of prices persists in the presence of heterogeneous loyal consumers in the market. Sinitsyn (2012) studies promotions considering two firms, each selling two complementary products. Bell et al. (1999) provide evidence on the efficacy of price promotions, by decomposing the total price elasticity for 173 brands. They find that price promotions result with demand expansion (25\%) and secondary demand effects or brand switching (75\%). Abby et al. (2015) show that increasing prices may also be beneficial when a new manufactured product enter a market.

Price promotions are also used when firms do not apply a clear mixed pricing strategy. For example, promotions are used as a tool to discriminate between stockpilers and non-stockpilers, between heavy and 
light users, or between consumers with heavy vs. low cost of time. Price promotions may induce consumers to adopt a behavior where they stockpile goods when prices are low (Helsen and Schmittlein, 1992; Assunção and Meyer, 1993).

\section{Behavioral implications of price changes}

The extant literature that establishes the behavioral relationship between fluctuating posted prices and transacted prices has relied primarily on analysis of staple goods such as peanut butter (Murthi et al., 2007), coffee (Han et al., 2001) and sweetened and unsweetened drinks (Kalyanaram and Little, 1994). Range Theory suggests that as consumers are exposed to price fluctuations, they become less sensitive to changes in prices (Volkmann, 1951). A series of experiments by Janiszewski and Lichtenstein (1999) have provided support to this theory and further suggested that consumers' perception of prices could be altered by manipulating the evoked price range. Additionally, as prices are perceived to follow some random process, consumers’ become uncertain about prices (Winer, 1989, Mellers 1980), which can further increase the range of prices that consumer consider as acceptable (Dickson and Sawyer, 1990; Winer, 1986).

A major factor influencing consumer behavior in the process of price changes is consumers' reference price. Reference price refers to consumers' perception of what is the "right" price for the good. The reference price can be an aggregation of external reference prices (i.e., what are the prices of comparable goods) and the internal reference price (i.e., internally established by the consumer). The creation of the latter may follow Helson's (1964) Adaptation-Level Theory, according to which it is the accumulation of current pervious elated stimuli (including their magnitude, range, as well as dispersion). Price volatility of staple goods has been shown to increase the reference price of consumers (Krishna and Johar, 1996). As the reference price increases, it could affect the perceived gains and losses. Similarly, price volatility has been shown to affect the range of price acceptance (Rao and Sieben, 1992; Kalyanaram and Little, 1994), and that "higher own-price volatility makes consumers more sensitive to gains and less sensitive to losses” (Han et al., 2001). Adding to this finding, Murthi et al. (2007) show that price variability can mitigate the price sensitivity of price-sensitive consumers. Effectively, they argue that "price volatility affects price sensitivity by increasing the level and range of reference prices, by lowering the importance 
weight that a customer places on price, and by affecting the perception of the difference between the actual price and the reference price.”

As mentioned earlier, the studies thus far focus primarily on staple goods, whereas our interest in perishable goods that are dynamically priced, such as airfares. This is an important difference, as for staple goods consumers may have the capacity to stockpile goods and decide rationally when to purchase the goods (Sterman and Dogan, 2015; Assunção and Meyer, 1993), and thus may exhibit strategic behavior. Furthermore, such behavior is significantly more challenging in the context of revenue managed goods. As part of this research, we show a possible correspondence between the staple goods literature and revenue managed goods.

\section{Data}

Our analysis of the relationship between price volatility and transacted fares, sales and revenue in the airline industry is based on data from two primary sources: an online fare aggregator ${ }^{1}$, to collect data on daily posted fare, and the U.S. Department of Transportation's (DOT) databases, to gather data on transacted prices, supply of seats, and sales.

From the aggregator website, we extracted the lowest available fare histories for 823 airport pairs. Five departure dates, one week apart from one another, were sampled, providing 5 fare histories for departures in the first quarter of 2008: February 26, March 4, 11, 18, and 25. We illustrate the range of variation of daily posted fare data in different markets in Figure 1. This figure shows two distinct types of markets. The right panel depicts a sample of airport pairs with very low fare variation over time. The only significant price movement in those markets is observed roughly two weeks before the flight takes place (which is in line with the intertemporal price discrimination between leisure and business travelers mentioned earlier). The left panel, on the other hand, depicts fare histories in markets that are more volatile. It is evident that the fare fluctuations are not limited to a certain time frame, and that in those markets the

\footnotetext{
${ }^{1}$ Specifically, we have collected fare data from Farecast, a website that by data-mining past fare histories, provided statistical inference about future movements of the lowest available fare as described in Etzioni et al. (2003). Following its sale to Microsoft in 2008, it was integrated into the Bing's platform.
} 
fares change quite frequently, and in considerable magnitude. Obviously, these differences in volatility capture information on the realization of RM practices in different markets. The question that emerges is whether these differences in price volatility levels embed information over and above the conventional variables such as competition, population, and other market characteristics. More specifically, we ask whether volatility levels help us learn more on transacted prices dispersion (as opposed to posted prices), fill rates, and revenues. Further, we seek initial evidence to whether those price fluctuations may have behavioral consequences on price sensitive consumers.
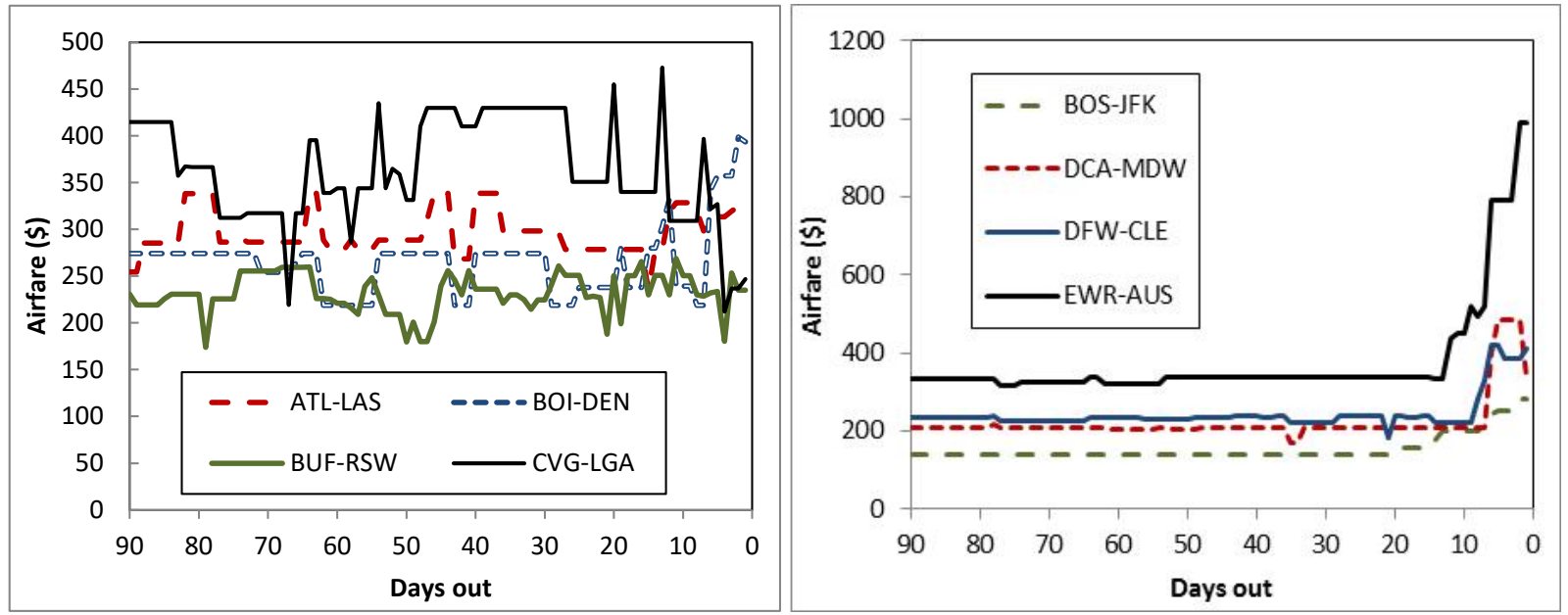

Figure 1. Sample of lowest available fare histories for airport pairs for 7-day return flights departing on March 4, 2008. Left panel highly volatile airfares, Right panel: highly stable pattern.

It should be noted that the observed pricing realization is relatively persistent in each market. To demonstrate, consider the CVG-LGA and the DCA-MDW markets. The former is a relatively volatile market, while the latter is a relatively stable market. In Figure 2 we demonstrate the behavior of five fare histories for each of these two markets. It is clear that the volatility level of each market is persistent across its five fare histories. It is evident that in the CVG-LGA market, depicted in the left pane of Figure 2, the price is rather unstable. By contrast, in the DCA-MDW market, the five fare histories show minimal differences over time, and changes occur primarily over the final week before departure. 


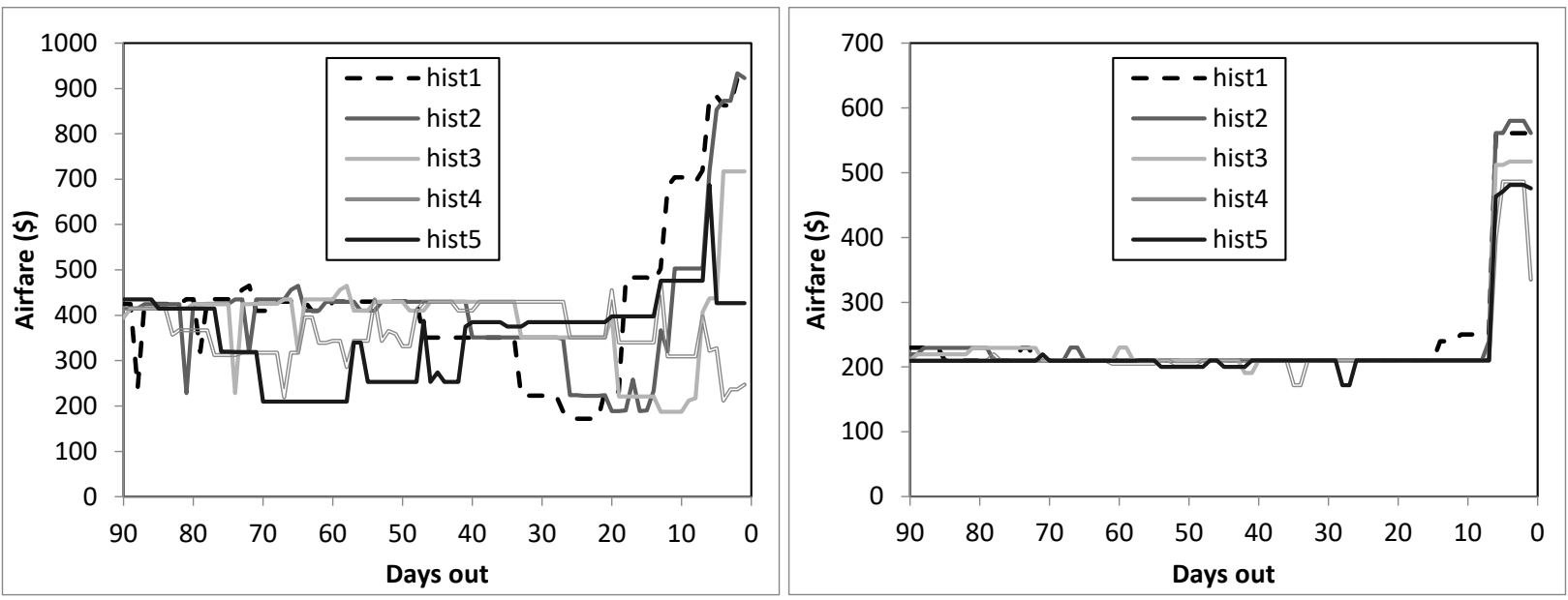

Figure 2. Different fare histories: CVG-LGA (left panel) and DCA-MDW (right panel)

From the DOT we gathered transacted fare data from the Origin and Destination Survey database (DB1B) which is a 10\% sample of transacted airline tickets provided by reporting carriers on a quarterly basis. Other variables, such as scheduled and performed flights, seating capacity, and load factors were derived from the DOT's T-100 database. ${ }^{2}$

\subsection{Measuring price volatility}

Our fare volatility measure is based on the common instruments used in the marketing literature, which also help capture possible perceptions of volatility by consumers. Namely, we refer to the measure devised and used by Kalyanaram and Little (1994), Han et al. (2002), and Murthi et al. (2007), while normalizing for potential differences in market price levels, as was done by Mantin and Gillen (2011), with the following formulation ${ }^{3}$ :

\footnotetext{
${ }^{2}$ There is a considerable body of literature that relies on the DB1B. Such research is typically concerned with the relationship between market structure and transacted airfares to derive appropriate public policies. Of interest in our context, however, are the studies on price levels and dispersion. Works such as Borenstein and Rose (1994), Hayes and Ross (1998), Dai et al. (2014), and Gerardi and Shapiro (2009), are primarily interested in the effect of competition on price dispersion. This stream of literature abstracts away from the intertemporal behavior of posted airfares. Several works have studied posted prices, such as the early work by Stavins (2001), and more recent contributions that use online sources (such as MaAfee and te Velde, 2007; and Gillen and Hazeldine, 2006). While previous studies have typically related to either posted prices or transacted prices, we relate to both and examine the link between posted and transacted airfares.

${ }^{3}$ In the marketing literature, a simple price volatility measure can be used as prices of goods from the same category are compared. Such an exponential smoothing method is preferred over other measures as "it captures the price patterns by giving different weights to recent relative to more distant changes in prices” (Han et al., 2001).
} 


$$
\text { PVOLN }_{m h t}=\theta P V O L N_{m h t+1}+(1-\theta)\left(\frac{P_{m h t}}{P_{m h t+1}}-1\right)^{2}, \text { with PVOLN } \operatorname{PL}_{m 90}=0,
$$

where PVOLN $m t$ is the price volatility of market $m$ in fare history $h$ at $t$ days prior to the flight and $\theta$ is the smoothing constant that can take any value between 0 and 1 . We considered several values of $\theta$. Qualitatively, the results are similar and herein we present only the results for the case of $\theta=0$ as it captures the full magnitude of price changes. ${ }^{4}$

Since our objective is to obtain market volatility levels, we calculated the vector of price volatilities on a market from $t=90$ days out to $=1$, for each of the five fare histories collected. We then averaged the results for each fare history, yielding five measures of volatility, one for each fare history. These five measures where averaged for each market, which resulted in one volatility measure per market. Our measure PVOLN90 captures the entire fare history (from 90 days out until 1 day out) on the route and is calculated as follows:

$$
\text { PVOLN } 90_{m}=\frac{\sum_{h=1}^{5} \sum_{t=1}^{90} P V O L N_{m h t}}{90} .
$$

In the appendix, we explore an alternative measurement of price volatility which is based on the degree of price predictability.

\subsection{Market Performance Variables}

We estimate the relationship of several market level performance variables and fare volatility. The first measure captures the average transacted prices in each market. Specifically, AveragePaidFareKM considers the average price paid by passengers on non-stop flights for an itinerary on a route divided by the direct distance (measured in kilometers). This metric is also known as yield, or the revenue per passenger kilometer, and was calculated based on averages of transactions in the Origin and Destination Survey sample (DB1B). As the DB1B includes transactions made under loyalty programs and other special benefits, any transaction smaller than $\$ 50$ was removed from our sample.

\footnotetext{
${ }^{4}$ In their formulation of the price reference formation, Mayhew and Winer (1992) use only the most recent price, which is equivalent to setting $\theta=0$ in our context.
} 
The second measure relating to transacted prices is the Gini coefficient of prices. The Gini coefficient measures the degree of dispersion, and its values range between 0 and 1 , with the former representing a market where all passengers paid the same fare and a value of 1 indicates the highest degree of inequality. After sorting the transacted fares from the cheapest to the most expensive, the Gini variable is formally defined as

$$
\operatorname{Gini}_{m}=\frac{2 \sum_{i=1}^{n} i y_{i}}{n \sum_{i=1}^{n} y_{i}}-\frac{n+1}{n}
$$

where $\operatorname{Gini}_{m}$ is the Gini measure of market $m$; $y_{i}$ is $i^{\text {th }}$ least expensive itinerary documented on DB1B for travel on the route during the quarter; and $n$ is the number of itineraries (i.e., the market enplanements) documented on the route on DB1B during the quarter. Since the Gini coefficient is bounded between 0 and 1, we estimate the Gini log-odds ratio which is given by GiniLogOdds $s_{m}=\ln \left(\frac{\operatorname{Gini}_{m}}{1-\operatorname{Gini}_{m}}\right)$, a measure that is unbounded.

Beyond transacted fares, we also study the relationship between price volatility and sales volume. For each market we compute the FillRate, which is the ratio between the total number of passengers who traveled on a route during the quarter to the total number of seats that where available in this market. The fill rate for each market was calculated using the T-100 database of the Department of Transportation by aggregating the seating capacity and enplanement during the quarter.

The final variable of interest is the total generated revenue in each market. Using the above measures, we generate a new normalized revenue measure variable RevenueRate. We define this measure as the product of the market's fill rate and the market's average normalized transacted fare on the route. Formally, we have RevenueRate $=$ AveragePaidFareKM $\cdot$ FillRate .

\subsection{Explanatory Variables}

The variables affecting airfare can be classified into two broad groups: route characteristics and market structure. 
We first describe our route characteristics variables. In line with the method used by Gerardi and Shapiro (2009), we collected data on the great circle distance for each airport pair (Distance), the population of each airport's metropolitan area size, as well as the income of the metropolitan area from the U.S. Department of Commerce, Bureau of Economic Analysis (BEA). Using the data from the BEA we further derived the income per capita of the population within the metropolitan area. Consistent with the literature, we have accounted for the average population (AvgPop) served by both origin and destination airports, as well as the average income per capita (AvgIncPop) of the corresponding origin and destination metropolitan areas. To control for the airlines' long term decisions about seat supply in the market, we also generate a measure of the total seating capacity in a market, MarketSeats.

We also adopt Gerardi and Shapiro's (2009) categorization of markets as leisure and/or business markets. Leisure markets are as markets with mainly price sensitive leisure passengers. Leisure is a dummy variable that equals 1 when either of the airports in the market is classified as a leisure destination, which occurs if the ratio of the accommodation earnings to the total nonfarm earnings corresponding to the metropolitan area where this airport is located exceeds 0.85 . Business is a dummy variable and such markets are termed by Geradi and Shapiro (2009) as big-city routes. If both origin and destination airports belong to the largest 30 metropolitan areas, then the market is defined as a business market (i.e., our Business variable is assigned a value of 1 ).

Market structure variables capture the competitive pressure in each market. We make use of two popular measures: Herfindahl-Hirschman Index $(H H I)$, which is the competitive index that quantifies the degree of market concentration, and the presence of low cost carriers (LCC). The HHI is defined as the squared market shares of carriers on a route, where the market share is calculated using MarketSeats variable, and the distribution of available seats between carriers. Thus, a value of 1 corresponds to a monopoly setting whereas a value of 0 reflects perfect competition. The competitive pressure measured by the HHI has been shown to induce lower airfares (e.g., Borenstein and Rose, 1994, and Dana, 1999). Low cost carriers (LCCs) impose a unique competitive pressure on airfares (Goolsbee and Syverson, 2005). LCCs possess a different operational mode than the traditional full service carriers. Specifically, LCCs have 
leaner operations that are facilitated by point-to-point service, they offer a single fare class, and operate a single airplane type. Accordingly, the airfare transacted by LCCs is significantly lower than the fare transacted by full service carriers. To account for the pressure stemming from LCCs, we measure the market share of LCCs on each airport pair based on the share of the total number of passenger enplanements by LCCs. The list of LCCs include AirTran Airways, Allegiant Air, JetBlue Airways, Southwest Airlines, Spirit Airlines, Sun Country Airlines, USA3000 Airlines, Virgin America, and Frontier.

We also control for the airport sizes by accounting for the number of passengers they served. This measure of airport activity could stem from locational rents of the airport (i.e., higher if located near a large metropolitan area), or from serving as a hub for certain carriers. Such an attribute can effect pricing, as, for example, an airport may charge carriers and passengers a premium if it has a high level of activity. We use the average number of passengers at both origin and destination airports (AvgAirportPAX). To derive this measure, we have used airport enplanement data from the FAA's website. We also consider an alternative measure that accounts for the presence of an airline's hub in a market. Specifically, we include dummy variables for each airline, HubAirline ${ }_{m i}$, each takes a value of 1 if either the origin or the destination airport of market $\mathrm{m}$ is a hub of Airline $i, i \in\{$ Airtran, Alaska, American, Continental, Delta, Frontier, Jet Blue, Midwest, Northwest, Southwest, Spirit, Sun Country, United, US, and Virgin\}, and 0 otherwise.

Table 1 provides summary statistics of these variables in our sample. The number of route observations in our sample is of 823 airport pairs, with an average transacted fare of 19 cents per Kilometer. The average stage length of the sampled routes is of about $1132 \mathrm{~km}$, and these routes have about 80,000 market seats on average, with considerable variation between routes. The table also shows that the average population of the metropolitan areas sampled is of approximately 2.5 million people and the average per capita income in our sample is of about US \$25,800. It is also evident that the share of LCCs and the competition index HHI, vary considerably between markets with a standard deviation of 0.318 and 0.257 , 
respectively. Finally, our volatility measure shows that the average price change on a route is approximately $1.2 \%$, and the highest fare volatility on a route in our sample is of approximately $12 \%$.

Table 1. Summary statistics

\begin{tabular}{lccccc}
\hline \hline Variable & Obs & Mean & Std. Dev. & Min & Max \\
\hline \hline Distance (1000 km) & 823 & 1.132 & 0.633 & 0.109 & 2.724 \\
\hline HHI (seats) & 823 & 0.643 & 0.257 & 0.193 & 1.000 \\
\hline LCCshare & 823 & 0.230 & 0.318 & 0.000 & 1.000 \\
\hline Market Seats (m) & 823 & 0.080 & 0.072 & 0.000 & 0.500 \\
\hline AvgPop (m) & 823 & 2.525 & 2.394 & 0.220 & 9.529 \\
\hline AvgIncPop (K\$) & 823 & 2.581 & 2.486 & 0.191 & 9.531 \\
\hline AvgAirportPax (m) & 823 & 15.002 & 6.121 & 3.332 & 39.879 \\
\hline PVOLN90 & 823 & 0.012 & 0.010 & 0.001 & 0.120 \\
\hline Business & 823 & 0.382 & 0.486 & 0.000 & 1.000 \\
\hline Leisure & 823 & 0.139 & 0.346 & 0.000 & 1.000 \\
\hline \hline AveragePaidFareKM (\$) & 823 & 0.188 & 0.143 & 0.063 & 1.651 \\
\hline GiniLogOdds & 823 & -1.055 & .280 & -2.033 & -0.118 \\
\hline FillRate & 823 & 0.762 & 0.097 & 0.337 & 1.000 \\
\hline RevenueRate (RASK) & 823 & 0.166 & 0.095 & 0.040 & 1.338 \\
\hline \hline
\end{tabular}

\section{What information can be learned from price volatility?}

In this section, we empirically explore the degree to which price volatility embeds information about market performance measures, beyond the information embedded in commonly used variables. To that end, we estimate the following linear reduced-form equations:

$$
\begin{aligned}
& \text { PredVar }_{m}=\alpha_{0}+\alpha_{1}{\text { PVOLN } 90_{m}}+\alpha_{2} \text { KM }_{m}+\alpha_{3} \text { HHI }_{m}+\alpha_{4} \text { LCCShare }_{m}+\alpha_{5} \text { MarketSeats }_{m}+ \\
& \alpha_{6} \text { AvgPop }_{m}+\alpha_{7} \text { AvgIncPop }_{m}+\alpha_{8} \text { Business }_{m}+\alpha_{9} \text { Leisure }_{m}+\alpha_{10} \text { AvgBoarding }_{m}+ \\
& \alpha_{11} \text { AirportHub }_{m}+\varepsilon_{m},
\end{aligned}
$$

where PredVar $r_{m}$ is the predicted variable in market $m$, which is one of the following: AveragePaidFareKM, GiniLogOdds, FillRate, or RevenueRate. Hence, for each predicted variable, we carry out several estimations based on equation (1). AirportHub is either AvgBoarding or the series of HubAirline dummy variables. In $\S 5.1$ we look at implications of price volatility on transacted prices. In $\S 5.2$ we focus on the 
volume of sales and generated revenue and accordingly the predicted variables are FillRate, and RevenueRate, respectively.

\subsection{Price Volatility and Transacted Fares}

We start by analyzing whether the daily volatility of posted prices embeds unique information about the average fare paid by consumers. Table 2 presents the regression results for different specifications where the dependent variable is the fare paid for each kilometer traveled. In specification 1, Airport activity is controlled for by including the HubAirline dummies, whereas in specification 2, AvgBoarding is included instead.

Before discussing the coefficients of the price volatility measures, we note that traditional explanatory variables behave as expected. Namely in Estimation 1, the transacted price per km (FareKM) decreases with the length of the flight (Distance) as with longer flights airlines can fly longer portion at cheaper cruising speeds and can use larger and more efficient aircrafts; it decreases in the proportion of seats offered by LCCs (LCC share) since those carriers have a leaner operational mode. The transacted price also decreases with the supply of seats in the market (MarketSeats); and it decreases in the 'hubness' of the airport (AvgBoard); and increases with the income levels (AvgIncPop) and when the market is classified as a business route. Interestingly, HHI, AvgPop and Leisure do not emerge as significant variables in predicting the average levels of transacted fares. Possibly, they provide no additional information after controlling for the other variables.

From the first two columns of Table 2, it is evident that volatility is positively correlated with the average transacted prices. Specifically, these regressions reveal that an increase of one percentage point in the volatility of the posted airfares is associated with an increase of $\$ 1.58$ - $\$ 1.77$ per $100 \mathrm{~km}$. Thus, volatility embeds information about market performance with respect to relative price levels per Kilometer. Many reasons may lead to this, perhaps volatility is the outcome of the higher margins estimated, as increased competition for those markets yields more price changes. Another possibility is that, consistent with marketing literature, it may be that as price volatility increases, consumers become less sensitive to price, which ultimately results with higher paid prices. Regardless of the reasons, these results suggest a 
new metric that can help managers, practitioners and passengers learn about the performance in different markets.

Table 2. Average Transacted FareKM and Gini of Transacted Fares

\begin{tabular}{|c|c|c|c|c|}
\hline & \multicolumn{2}{|c|}{ FareKM } & \multicolumn{2}{|c|}{ GiniLogOdds } \\
\hline & (1) & (2) & (1) & (2) \\
\hline \multirow[t]{2}{*}{ PVOLN90 } & $1.771 * *$ & $1.585 * *$ & $5.578 * *$ & $5.570 * *$ \\
\hline & $(0.395)$ & $(0.406)$ & $(0.739)$ & $(0.759)$ \\
\hline \multirow[t]{2}{*}{ Distance (k) } & $-0.129 * *$ & $-0.152 * *$ & $0.0697 * *$ & $0.101 * *$ \\
\hline & $(0.00779)$ & $(0.00817)$ & $(0.0146)$ & $(0.0153)$ \\
\hline \multirow[t]{2}{*}{ HHI seats } & -0.00214 & 0.0279 & 0.0437 & 0.0221 \\
\hline & $(0.0173)$ & $(0.0177)$ & $(0.0324)$ & $(0.0330)$ \\
\hline \multirow[t]{2}{*}{ LCC share } & $-0.0688 * *$ & $-0.0785 * *$ & $-0.369 * *$ & $-0.368 * *$ \\
\hline & $(0.0136)$ & $(0.0146)$ & $(0.0254)$ & $(0.0273)$ \\
\hline \multirow[t]{2}{*}{ MarketSeats (m) } & -0.0428 & $-0.169 *$ & $0.428 * *$ & $0.639 * *$ \\
\hline & $(0.0789)$ & $(0.0708)$ & $(0.147)$ & $(0.132)$ \\
\hline \multirow[t]{2}{*}{ AvgPop (m) } & 0.00273 & 0.000980 & $0.0157 * *$ & $0.0172 * *$ \\
\hline & $(0.00175)$ & $(0.00190)$ & $(0.00327)$ & $(0.00355)$ \\
\hline \multirow[t]{2}{*}{ AvgIncPop (k) } & $0.00324+$ & 0.00171 & $0.0140 * *$ & $0.0146^{* *}$ \\
\hline & $(0.00171)$ & $(0.00185)$ & $(0.00320)$ & $(0.00347)$ \\
\hline \multirow[t]{2}{*}{ Business } & $0.0232 *$ & $0.0256 * *$ & $0.0428 *$ & $0.0501 * *$ \\
\hline & (0.00919) & $(0.00969)$ & $(0.0172)$ & $(0.0181)$ \\
\hline \multirow[t]{2}{*}{ Leisure } & 0.0140 & 0.00609 & $-0.0568 *$ & $-0.0972 * *$ \\
\hline & $(0.0128)$ & $(0.0138)$ & $(0.0239)$ & $(0.0259)$ \\
\hline \multirow[t]{2}{*}{ AvgBoard (m) } & $-0.00194 *$ & - & $0.00373 *$ & \\
\hline & $(0.000955)$ & & $(0.00179)$ & \\
\hline HubAirline Dummies & - & YES & & YES \\
\hline \multirow[t]{2}{*}{ Constant } & $0.337 * *$ & $0.332 * *$ & $-1.316^{* *}$ & $-1.313^{* *}$ \\
\hline & $(0.0183)$ & $(0.0181)$ & $(0.0343)$ & $(0.0339)$ \\
\hline$N$ & 823 & 822 & 823 & 822 \\
\hline adj. $R^{2}$ & 0.382 & 0.426 & 0.438 & 0.477 \\
\hline
\end{tabular}

To further learn about the information embedded in volatility of posted airfares, we now consider the dispersion of the transacted airfares as captured via the Gini coefficient. Similar to Gerardi and Shapiro (2009) we transform the Gini coefficient (which is bounded between zero and one) to the unbounded statistic Gini log-odds ratio. The results of the estimations are provided in the last two columns of Table 2. These results clearly reveal the significant relationship between the volatility of posted airfares and the 
dispersion of the transacted airfares. Intuitively, price volatility increases the range of different prices that are available to consumers, and with a greater range of available prices, one expects to encounter a wider dispersion of fares transacted by consumers.

Thus far, we have found that price volatility levels can embody information about transacted prices both in terms of level and dispersion: the more volatile prices are, the higher is the average transacted prices and the greater is their dispersion. In the presence of volatile prices, as consumers appear to pay more for their itineraries, does one expect the law of demand to prevail (that is, higher prices come with lower demand), or is price volatility associated with consumers paying more with no (or limited) other consequences? We address this question in the next subsection by exploring the relationship between price volatility and fill rates.

\subsection{Information about Fill Rates and Revenue}

We now turn to examine the relationship between price volatility and the volume of sales. The supply of seats in each market is a long term decision made by airlines. The most obvious mechanism used by airlines to increase their fill rates is pricing. Lower prices are expected to increase demand and vice versa. Indeed, one of the goals of RM systems is to minimize the quantity of unsold goods. Specifically, they seek to increase the load factor of their flights, as this is one of the major performance metrics in the airline industry.

Our estimation results, where the dependent variable is the fill rate, are provided in the first two columns of Table 3. The results suggest that an increase of one percentage point in the volatility of the posted airfares is associated with a decrease of 1.29 - 1.51 percentage points in the fill rate. This is an interesting result: higher price volatility levels indicate a lower sales volume. One percentage point decrease in the fill rate could impact an airline quite dramatically. This result could be expected considering that price volatility may reflect the level to which market demand is predictable.

Hence, higher price volatility is associated with higher transacted airfare, but lower fill rates. These two results have contradicting effects on revenue. Do airlines gain superior revenues in markets exhibiting higher level of price volatility? That is, do the associated higher transacted airfares compensate for the associated lower demand or vice versa? This question is addressed in the last two estimations in Table 3, 
which reveal that in markets with higher volatility levels, airlines yield higher revenues when compared to markets with lower volatility levels. Specifically, we find that for one percentage point increase in the volatility of prices, airlines experience an increase in revenue of \$1.13-1.27 per available seat kilometer.

Table 3. Fill Rate and Revenue Rate

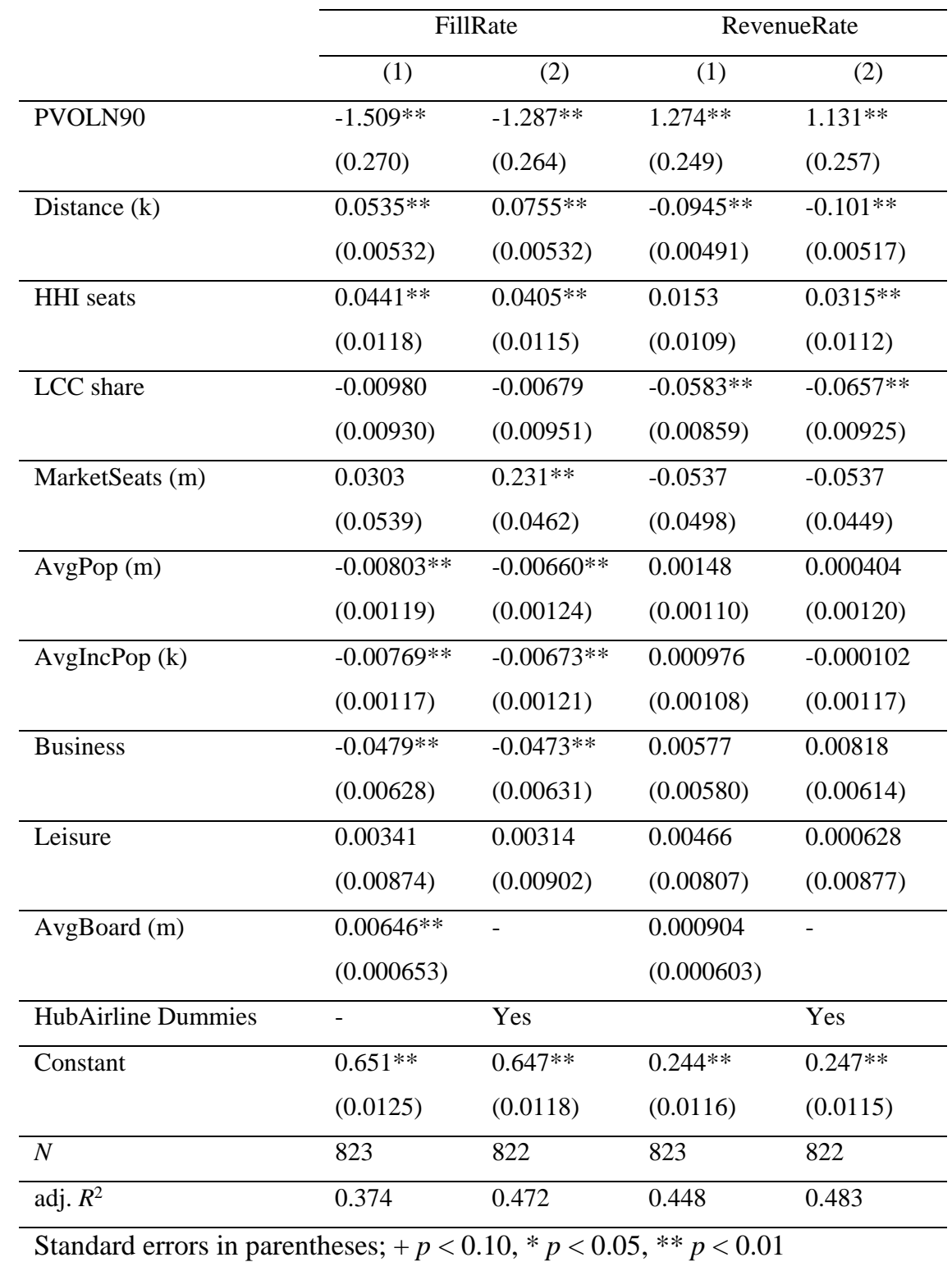

\section{Price Volatility and Consumer Behavior}

The analysis thus far has confirmed that price volatility levels embed information about market outcomes, beyond what is derived from conventional market variables. In this section, we seek evidence to whether 
the effect of price volatility on consumer behavior, which was documented in the context of staple goods, exists in the context of revenue managed goods as well. Namely, we test for evidence that with higher volatility, price sensitivity of consumers is reduced and greater revenue can be generated. The results of Section 5.1 can support the same logic that was found in the marketing literature with respect to staple goods, also for the context of revenue managed goods. That is, although consumers may be expecting the variations in prices of flights over time, the fact that prices are changing may lead consumers to be willing to pay a higher price, on average, for a flight. In this section we seek to provide evidence whether this phenomenon may indeed exist in the context of airline tickets, and more broadly of revenue managed goods.

For this purpose, we develop a two-stage model where price volatility and average posted price per Kilometer are endogenously estimated in the first stage, and revenue is estimated in the second stage. The average posted price per Kilometer is calculated using our 5 fare histories (h), each containing 90 days of fare observations ( $\mathrm{t}$ ), and is defined as follows for each market (m)

$$
\text { AvgPostedPriceKM }_{m}=\frac{\sum_{h=1}^{5} \sum_{t=1}^{90} P_{m h t}}{5 \cdot 90 \cdot \text { Distance }_{m}} .
$$

The reason for endogenizing the average posted price has to do with our instrument variables. With the estimation of the average posted price in the first stage, the market variables are not expected to affect the transacted prices in the second stage. In other words, since the average posted price captures the entire effect of market variables on pricing, market variables should not affect revenue beyond their influence on the posted fare. This allows for the utilization of distance and LCCShare as instrument variables in the first stage. Accordingly, in the first stage we estimate the following two models:

$$
\begin{aligned}
& \text { AvgPostedPriceKM }_{m}=\alpha_{0}+\alpha_{1} \text { Distance }_{m}+\alpha_{2} \text { AvgPop }_{m}+\alpha_{3} \text { AvgIncPop }_{m}+ \\
& \alpha_{4} \text { HHISeats }_{m}+\alpha_{5} \text { AvgBoard }_{m}+\alpha_{6} \text { MarketSeats }_{m}+\alpha_{7} \text { LCCShare }_{m}+\varepsilon_{m} . \\
& \text { and } \\
& \text { PVOLN9 } \text { PV }_{m}=\alpha_{0}+\alpha_{1} \text { Distance }_{m}+\alpha_{2} \text { AvgPop }_{m}+\alpha_{3} \text { AvgIncPop }_{m}+ \\
& \alpha_{4} \text { HHISeats }_{m}+\alpha_{5} \text { AvgBoard }_{m}+\alpha_{6} \text { MarketSeats }_{m}+\alpha_{7} \text { LCCShare }_{m}+\varepsilon_{m} .
\end{aligned}
$$

And in the second stage we model the revenue at the route level as follows: 


$$
\begin{aligned}
& \text { RevenueRate }_{m}=\beta_{0}+\beta_{1} \text { FittedPVOLN90 }_{m}+\beta_{2} \text { FittedAvgPostedPriceKM }_{m}+ \\
& \beta_{3} \text { AvgPop }_{m}+\beta_{4} \text { AvgIncPop }_{m}+\beta_{5} \text { HHISeats }_{m}+\beta_{6} \text { AvgBoard }_{m}+\beta_{7} \text { MarketSeats }_{m}+ \\
& \beta_{8} \text { LCCShare }_{m}+\varepsilon_{m}
\end{aligned}
$$

where FittedPVOLN90 and FittedAvgPostedPriceKM are the fitted values of PVOLN90 and AvgPostedPriceKM from the first stage of the model.

We have estimated this model separately for business markets and for leisure markets, expecting volatility to affect consumer behavior of price sensitive consumers, and thus to be significant only in leisure markets. Indeed, our estimations showed insignificant effects of volatility on revenue in business markets. However, in the estimation of leisure markets the effect of volatility was found significant, supporting the notion that consumers become less price sensitive with increased volatility and therefore the market becomes more profitable.

The first stage estimation results for leisure markets are provided in Table $\mathbf{4}$. From the table one can see that price volatility is significantly and negatively related to the presence of low cost carriers in the market, as well as to the average income per capita. With respect to AveragePostedFareKM, one can observe that the relationships with the independent variables hold as expected. The larger the distance the smaller the amount paid per kilometer traveled; and the downward pressure on prices is evident from the significantly negative coefficient of the LCC variable. 
Table 4. First stage estimations

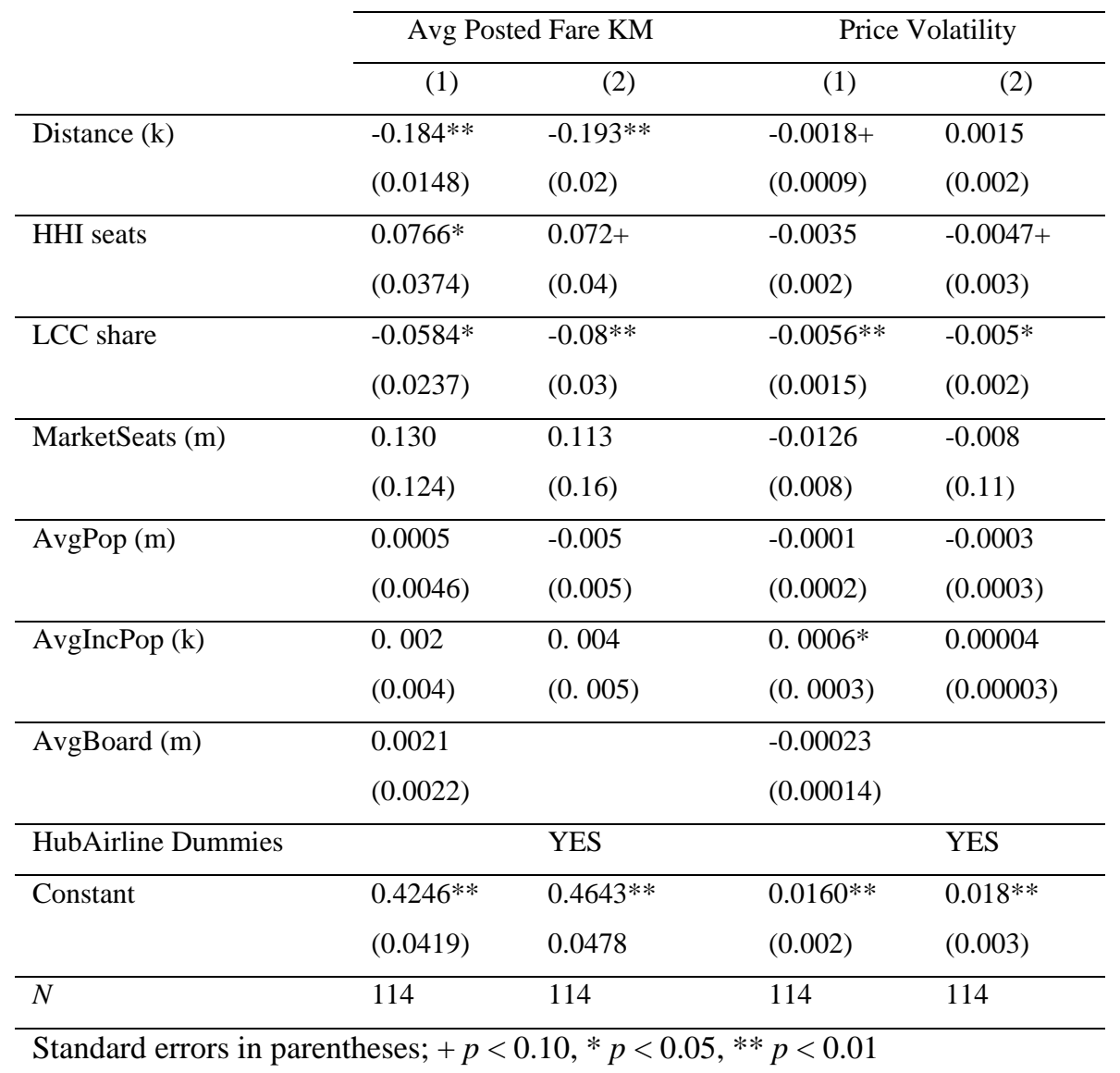

The results of our second stage analysis are reported in Table $\mathbf{5}$. As can be seen, the variables estimated in the first stage are highly significant in the second stage. Most importantly, after endogenously modelling the posted price and controlling for it, volatility is positive and significant at the $1 \%$ level in its effect on the generated revenue. These results are in line with the idea that consumers' reaction to price changes in revenue managed goods, is similar in fashion to their behavioral reaction to changes in prices of staple goods, and that they become less price sensitive, allowing carriers to generate more revenue. 
Table 5. Second stage estimations

\begin{tabular}{|c|c|c|}
\hline \multirow{3}{*}{ Fitted PVOLN90 } & \multicolumn{2}{|c|}{ RevenueRate } \\
\hline & (1) & $(2)$ \\
\hline & $6.472 * *$ & $9.64 * *$ \\
\hline & $(2.429)$ & $(4.87)$ \\
\hline \multirow[t]{2}{*}{ Fitted Avg Posted Fare KM } & $0.448 * *$ & $0.422 * *$ \\
\hline & $(0.05)$ & $(0.088)$ \\
\hline \multirow[t]{2}{*}{ HHI seats } & $0.057 * *$ & 0.084 \\
\hline & $(0.022)$ & $(0.038)$ \\
\hline \multirow[t]{2}{*}{ MarketSeats (m) } & 0.0877 & 0.102 \\
\hline & $(0.0765)$ & $(0.13)$ \\
\hline \multirow[t]{2}{*}{ AvgPop (m) } & 0.000007 & 0.00025 \\
\hline & $(0.0022)$ & $(0.0036)$ \\
\hline \multirow[t]{2}{*}{ AvgIncPop (k) } & 0.0005 & 0.0006 \\
\hline & $(0.0002)$ & $(0.0004)$ \\
\hline \multirow[t]{2}{*}{ AvgBoard (m) } & -0.0010 & \\
\hline & $(0.0012)$ & \\
\hline HubAirline Dummies & & YES \\
\hline \multirow[t]{2}{*}{ Constant } & $-0.06 *$ & $0.124+$ \\
\hline & $(0.027)$ & $(0.067)$ \\
\hline$N$ & 114 & 114 \\
\hline Centered $R^{2}$ & 0.72 & 0.54 \\
\hline Uncentered $R^{2}$ & 0.93 & 0.88 \\
\hline
\end{tabular}

\section{Concluding remarks}

Revenue management is a tool commonly used by firms in numerous industries to boost the revenue generated from their stock of goods. The application of this tool results with prices that may fluctuate over time. The fact that different markets exhibit different volatility levels, allows us to investigate whether the different outcomes of RM practices embed market level information. In this paper we have explored the relationship between the volatility of posted prices of revenue managed good and performance measures such as transacted prices and their dispersion, the sales levels, as well as the revenue generated. 
Our results complement the insights from the existing literature regarding market variables and performance, while providing additional understanding about fluctuating prices and the information they embed about market performance.

Our results show that volatility levels reflect much about the interaction between sellers and their consumers in numerous ways. In particular, we showed that volatile prices are associated with higher transacted prices and increased distribution of these prices (as captured by the Gini coefficient). Furthermore, we found that increased volatility is associated with lower sales levels (as captured by the fillrates of the aircrafts). This reveals that while the revenue per unit sold increases, the volume of sales decreases. This initiated the exploration of the revenue generated, which, as captured by the RASK measure, suggests that it is higher with increased fare volatility levels. These results can help managers, practitioners, consumers and academics. Managers and practitioners can use the results presented in this paper to learn about potential markets to invest in, and the associated performance outcomes that may come as a result of such investments. This may also help managers quickly learn about where RM is most effective and where RM practices can be improved, simply by examining the volatility level of a market. This research also suggests that passengers may use volatility measures to help them behave more strategically. That is, based on this research, a passenger may learn that when a few options exist for traveling, it is better to travel on a less volatile route, as the average payed price per kilometer flown would be lower. For academics this research may provide a starting point for further analysis on the relationship between performance and volatility, and understanding the empirical implications of using RM systems.

We have also provided deeper insights into linkage between volatility and consumer behavior, by examining whether there is evidence supporting the notion that the behavior of price sensitive consumers may be effected by volatility levels. Using a two-stage estimation model, we found support for the effect of volatility levels on consumers' price sensitivity. The link between fluctuating prices and consumer behavior has been studied heavily in the context of perishable goods, our initial results, relating to possible consequences in the context of revenue-managed goods, can serve as a starting point for more research in this direction 
Many other directions for future research can be suggested based on this work. While our analysis was carried out in the context of US domestic aviation, it remains to explore whether the insights gravitate to international travel, where the planning process at the consumer end may start much earlier than with domestic travel. Further, other types of revenue-managed goods can be explored, such as sales of commercial slots, which expand the scope of interaction to inter-firm rather than firm-consumers.

\section{Appendix: Alternative approach to measuring volatility}

In this appendix we show the robustness of our findings, when discarding predictable price changes induced by the temporal proximity of departure date. In aviation markets, it can be argued that the price tends to exhibit a somewhat predictable pattern of a fare increase as departure date approaches. Therefore, in this section we model price volatility in airline markets using an approach which addresses this concern. For each of the markets we fit a commonly observed fare history and capture the dynamic deviations from this fitted line to derive a modified price volatility measure.

Specifically, we adopt the pricing mechanism from Malighetti et al. (2009):

$$
p_{m t}=\mu_{m}+\frac{1}{\alpha_{m} \cdot\left(1+\beta_{m} \cdot t+\gamma_{m} \cdot t^{2}\right)}
$$

where $\mu$ indicates the minimal price level, and where $\alpha, \beta$ and $\gamma$ control for the shape of the curve. Note that $\alpha$ reflects the level of prices towards the departure date, with lower $\alpha$ corresponding to a higher last minute fare, $\beta$ adjusts the speed of increase in fare, whereas $\gamma$ change the curvature. This pricing formulation is powerful in its ability to capture last-minute price drops (for example as in the DCA-MDW market).

Using the five fare histories, we fit the nonlinear function (5) by method of least squares to obtain the estimates for each of the markets. In the estimation process, we have eliminated three markets for which the projected fares explode. The resulting estimates are illustrated in Figure 3, noting the difference between the highly predictable DCA-MDW market and the highly volatile CVG-LGA. 

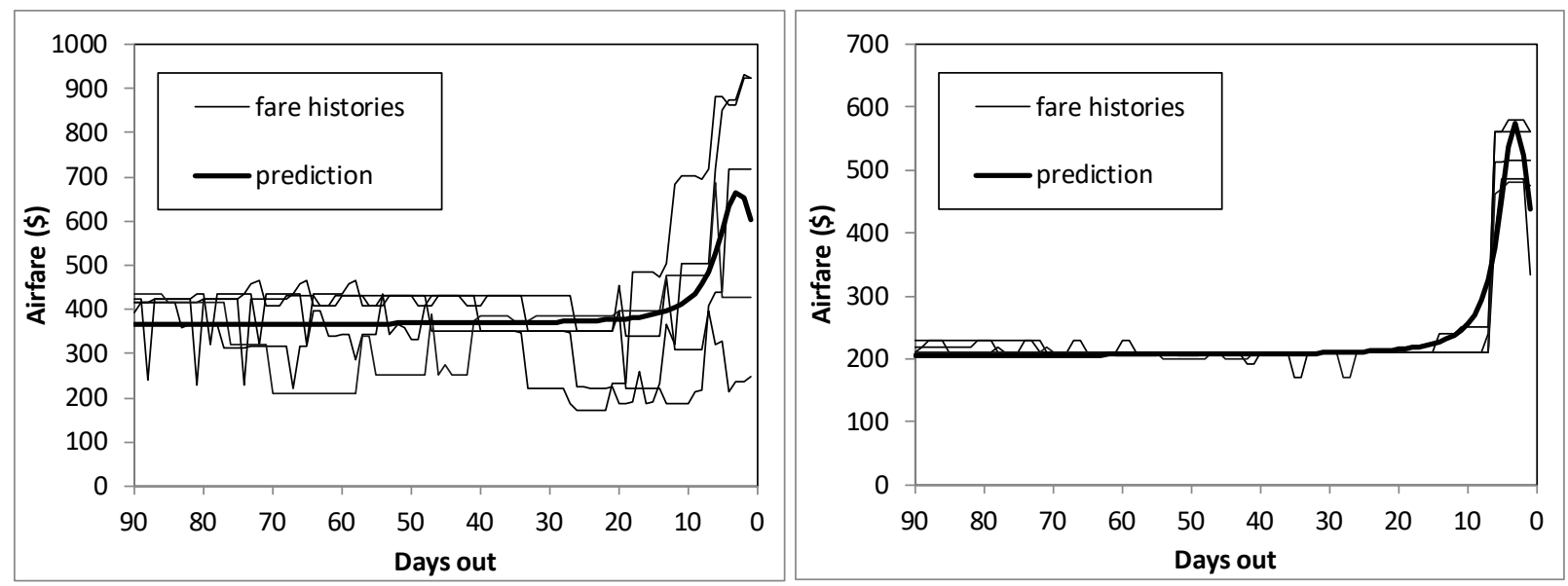

Figure 3. Different fare histories and the best line fit: CVG-LGA (left panel) and DCA-MDW (right panel)

Next, we normalize the fare history by further accounting for the deviations from the predicted fare. Specifically, we divide each observed fare by the predicted fare, and resorting to our earlier method, we have:

$$
\operatorname{NewPVOLN} N_{m t}=\theta N e w P V O L N_{m t+1}+(1-\theta)\left(\frac{P_{m t} / \hat{P}_{m t}}{P_{m t+1} / \hat{P}_{m t+1}}-1\right)^{2} \text {, with NewPVOLN } N_{m 90}=0 \text {, }
$$

where $\widehat{P}_{m t}$ denotes the fitted fare in market $\mathrm{m}$. For example, in the highly predictable DCA-MDW market, the resulting NewPVOLN is 0.01174 (whereas PVOLN=0.02064). By contrast, in the highly volatile CVGLGA the NewPVOLN is only 0.03015 (compared with PVOLN of 0.02972).

The estimation results, which are provided in Table 6, clearly indicate the robustness of our earlier insights, where price volatility is associated with increased transacted fares as well as increased transacted fare dispersion, while fill rate is lower bit with an overall significant increase in the revenue generated. 
Table 6. Estimations with NewPVOLN

\begin{tabular}{|c|c|c|c|c|}
\hline & \\
\hline & FareKM & GiniLogOdds & FillRate & RevenueRate \\
\hline & (1) & (2) & (3) & (4) \\
\hline \multirow[t]{2}{*}{ NewPVOLN90 } & $0.859 * *$ & $4.048 * *$ & $-1.184 * *$ & $0.626 * *$ \\
\hline & $(0.309)$ & $(0.576)$ & $(0.209)$ & $(0.195)$ \\
\hline \multirow[t]{2}{*}{$\mathrm{KM}(\mathrm{k})$} & $-0.132 * *$ & $0.0658 * *$ & $0.0545 * *$ & $-0.0969 * *$ \\
\hline & $(0.00782)$ & $(0.0146)$ & $(0.00530)$ & $(0.00495)$ \\
\hline \multirow[t]{2}{*}{ HHI seats } & -0.00104 & 0.0471 & $0.0429 * *$ & 0.0160 \\
\hline & $(0.0175)$ & $(0.0326)$ & $(0.0118)$ & $(0.0111)$ \\
\hline \multirow[t]{2}{*}{ LCC share } & $-0.0713 * *$ & $-0.375^{* *}$ & -0.00726 & $-0.0601 * *$ \\
\hline & $(0.0137)$ & $(0.0256)$ & $(0.00930)$ & $(0.00869)$ \\
\hline \multirow[t]{2}{*}{ MarketSeats (m) } & -0.0476 & $0.441 * *$ & 0.0250 & -0.0564 \\
\hline & $(0.0799)$ & $(0.149)$ & $(0.0541)$ & $(0.0505)$ \\
\hline \multirow[t]{2}{*}{ AvgPop (m) } & 0.00246 & $0.0156^{* *}$ & $-0.00791^{* *}$ & 0.00130 \\
\hline & $(0.00176)$ & $(0.00329)$ & $(0.00119)$ & $(0.00111)$ \\
\hline \multirow[t]{2}{*}{ AvgIncPop (k) } & $0.00294+$ & $0.0133^{* *}$ & $-0.00754^{* *}$ & 0.000756 \\
\hline & $(0.00172)$ & $(0.00321)$ & $(0.00117)$ & $(0.00109)$ \\
\hline \multirow[t]{2}{*}{ Business } & $0.0255^{* *}$ & $0.0516^{* *}$ & $-0.0506 * *$ & 0.00737 \\
\hline & $(0.00931)$ & $(0.0174)$ & $(0.00631)$ & $(0.00589)$ \\
\hline \multirow[t]{2}{*}{ Leisure } & 0.0138 & $-0.0527 *$ & 0.00124 & 0.00452 \\
\hline & $(0.0130)$ & $(0.0242)$ & $(0.00878)$ & $(0.00820)$ \\
\hline \multirow[t]{2}{*}{ AvgBoard (m) } & $-0.00172+$ & $0.00340+$ & $0.00661^{* *}$ & $0.00105+$ \\
\hline & $(0.000974)$ & $(0.00182)$ & $(0.000660)$ & $(0.000616)$ \\
\hline \multirow[t]{2}{*}{ Constant } & $0.351 * *$ & $-1.287 * *$ & $0.643 * *$ & $0.253 * *$ \\
\hline & $(0.0181)$ & (0.0338) & $(0.0123)$ & $(0.0115)$ \\
\hline$N$ & 820 & 820 & 820 & 820 \\
\hline adj. $R^{2}$ & 0.373 & 0.433 & 0.375 & 0.437 \\
\hline
\end{tabular}

Standard errors in parentheses; $+p<0.10,{ }^{*} p<0.05,{ }^{* *} p<0.01$

\section{References}

Abbey, J. D., Blackburn, J. D., and Guide, V. D. R. 2015. Optimal pricing for new and remanufactured products. Journal of Operations Management, 36, 130-146.

Anderson, C. K. and J. G. Wilson. 2003. Wait or buy? The Strategic Consumer: Pricing and Profit Implications. Journal of the Operational Research Society, 54(3): 299-306.

Assunção, J. L., and Meyer, R. J. 1993. The rational effect of price promotions on sales and consumption. Management Science, 39(5), 517-535. 
Bell, D. R., Chiang, J., and Padmanabhan, V. 1999. The decomposition of promotional response: An empirical generalization. Marketing Science, 18(4), 504-526.

Belobaba, P. P. (1989). Application of a Probabilistic Decision Model to Airline Seat Inventory Control. Operations Research, 37(2), 183-197.

Borenstein, S. and N. L. Rose. 1994. Competition and Price Dispersion in the U.S. Airline Industry, Journal of Political Economy, 102 (4): 653-683.

Brynjolfsson, E. and M. D. Smith. 2000. Frictionless Commerce? A Comparison of Internet and Conventional Retailers. Management Science, 46(4): 563-585.

Chioveanu, I., and Zhou, J. 2013. Price competition with consumer confusion. Management Science, 59(11), 2450-2469.

Dai, M., Liu, Q., and Serfes, K. 2014. Is the Effect of Competition on Price Dispersion Non-Monotonic? Evidence from the US Airline Industry. Review of Economics and Statistics. 96(1): 161-170.

Dana, James D., Jr. 1999. Equilibrium Price Dispersion under Demand Uncertainty: The Roles of Costly Capacity and Market Structure. Rand Journal of Economics, 30: 632-60.

Ellison, G., and F. Ellison. 2009. Search Obfuscation, and Price Elasticities on the Internet. Econometrica, 77(2): 427-452

Etzioni, O., R. Tuchinda, C.A. Knoblock, and A. Yates. 2003. To buy or not to buy: mining airfare data to minimize ticket purchase price. In Proceedings of KDD03. ACM Press, 119-128.

Gerardi, K. S., and Shapiro, A. H. 2009. Does competition reduce price dispersion? New evidence from the airline industry. Journal of Political Economy, 117(1), 1-37.

Goolsbee, A., and C. Syverson. 2005. How Do Incumbents Respond to the Threat of Entry? Evidence from Major Airlines. NBER Working Paper No. 11072, National Bureau of Economic Research, Cambridge.

Han, S., Gupta, S., and Lehmann, D. R. 2001. Consumer price sensitivity and price thresholds. Journal of Retailing, 77(4), 435-456.

Hayes, K. J., Ross, L. B. 1998. Is Airline Price Dispersion the Result of Careful Planning or Competitive Forces? Review of Industrial Organization 13(5): 523-541.

Helsen, K., D.C. Schmittlein. 1992. Some characterizations of stockpiling behavior under uncertainty. Marketing Letters, 3(1): 5-16.

Kalyanaram, G., and Little, J. D. C. 1994. An empirical analysis of latitude of price acceptance in consumer packaged goods. Journal of Consumer Research, 21(December), 408-418.

Krishna, A., and Johar, G. V. 1996. Consumer perceptions of deals: biasing effects of varying deal prices. Journal of Experimental Psychology: Applied, 2(3), 187-206.

Malighetti, P., Paleari, S., and Redondi, R. 2009. Pricing strategies of low-cost airlines: The Ryanair case study. Journal of Air Transport Management, 15(4), 195-203. 
Mantin, B., and Gillen, D. 2011. The hidden information content of price movements. European Journal of Operational Research, 211(2), 385-393.

Mayhew, G. E., and Winer, R. S. 1992. An empirical analysis of internal and external reference prices using scanner data. Journal of Consumer Research, 19: 62-70.

Mellers, B. A. (1980). Configurality in multiple-cue probability learning. The American Journal of Psychology, 429-443.

Murthi, B. P. S., Haruvy, E., and Zhang, H. 2007. The effect of variability in price on consumer brand choice. Review of Marketing Science, 5(1).

Narasimhan, C. 1988. Competitive promotional strategies. Journal of Business, 427-449.

Netessine, S., and Shumsky, R. (2002). Introduction to the theory and practice of yield management. INFORMS Transactions on Education, 3(1), 34-44.

Phillips, R. L. 2005. Pricing and Revenue Optimization. Stanford University Press.

Raju, J. S., Srinivasan, V., and Lal, R. 1990. The effects of brand loyalty on competitive price promotional strategies. Management science, 36(3), 276-304.

Rao, A., and Sieben, W. A. 1992. The effect of prior knowledge on price acceptability and the type of information examined. Journal of Consumer Research, 19(September), 256-270.

Sinitsyn, M. 2008. Technical Note-Price Promotions in Asymmetric Duopolies with Heterogeneous Consumers. Management Science, 54(12), 2081-2087.

Sinitsyn, M. 2012. Coordination of price promotions in complementary categories. Management Science, 58(11), 2076-2094.

Stavins, J. 2001. Price discrimination in the airline market: The effect of market concentration. Review of Economics and Statistics, 83(1), 200-202.

Sterman, J. D., and Dogan, G. 2015. I'm not hoarding, I'm just stocking up before the hoarders get here: Behavioral causes of phantom ordering in supply chains. Journal of Operations Management, 39, 6-22.

Talluri, K. T. and G. J. van Ryzin. 2004. The Theory and Practice of Revenue Management, volume 68 of International Series in Operations Research and Management Science. Springer.

Varian, H. R. 1980. A model of sales. American Economic Review, 70(4): 651-659. 